\title{
Is Diabetic Nephropathy a Predicted Risk Factor? Kaplan-Meier and Multivariate Analysis of Confounding Risk Factors in Off-Pump Coronary Artery Bypass Grafting for Chronic Dialysis Patients
}

\author{
Shizu Oyamada, MD; Junjiro Kobayashi, MD; Osamu Tagusari, MD*; \\ Hiroyuki Nakajima, MD; Satoko Nakamura, MD**; \\ Toshikatsu Yagihara, MD; Soichiro Kitamura, MD
}

\begin{abstract}
Background: The purpose of this study was to investigate the preoperative risk factors of performing off-pump coronary artery bypass grafting $(\mathrm{OPCAB})$ in patients on chronic dialysis.

Methods and Results: The 41 consecutive patients on chronic dialysis who underwent OPCAB from February 2000 to April 2006 at the National Cardiovascular Center were studied retrospectively. Of them, 29 had diabetic nephropathy (DN group) and the remaining 12 did not (NDN group). There were significant differences in the duration of dialysis before surgery $(9.1 \pm 7.5$ years in NDN vs $4.2 \pm 5.5$ years in $\mathrm{DN}, \mathrm{P}=0.028)$ and low cardiac function (left ventricular ejection fraction $<30 \%)$, which was recognized only in the DN group $(7 / 29, \mathrm{P}=0.048)$. The early mortality rate was $6.9 \%(2 / 29)$ in the DN group and $16.7 \%(2 / 12)$ in the NDN group ( $\mathrm{P}=0.349)$. The actuarial survival rates in the $\mathrm{DN}$ group were $85 \%$ at 1 year, $45 \%$ at 3 years, and $30 \%$ at 5 years, whereas in the NDN group they were $71 \%, 49 \%$, and $49 \%$, respectively $(\mathrm{P}=0.789)$. Arteriosclerosis obliterans (ASO) and age ( $>65$ years) were independent risk factors of late death.

Conclusions: For patients on chronic dialysis ASO and aging were predicted risk factors for OPCAB, whereas diabetic nephropathy was not. (Circ J 2009; 73: 2056-2060)
\end{abstract}

Key Words: Diabetic nephropathy; Dialysis; Off-pump coronary artery bypass grafting

I $t$ is still controversial whether off-pump coronary artery bypass grafting (OPCAB) is more effective than conventional on-pump coronary artery bypass grafting $(\mathrm{CABG})$ in the population of poor prognosis patients. OPCAB is the most common strategy of CABG for lowrisk patients in Japan, ${ }^{1}$ but often there are patients with severe complications who require CABG and for whom either on-pump or off-pump surgery might be reasonable. A recent prospective study showed that chronic renal disease is independently associated with adverse long-term outcomes in a broad cohort of Japanese patients, ${ }^{2}$ making chronic dialysis one of the most high-risk preoperative comorbidities in Japan. These days, the number of patients on chronic dialysis is increasing in parallel with the increase in diabetes, which is known as the leading cause of chronic renal failure requiring dialysis. In general, natural prognoses for patients on chronic dialysis are worse for those with diabetic nephropathy than for non-diabetic nephropathy patients. According to The United Kingdom Prospective Diabetes Study (2003), the largest-scale prospective study of diabetic nephropathy, when serum creatinine levels increase over $2.0 \mathrm{mg} / \mathrm{dl}$, renal failure becomes end-stage, which requires dialysis within approximately 2.5 years and at which point the patient is likely to die within 3 years, ${ }^{3}$ with the major cause of death being cardiovascular disease. ${ }^{4,5}$

We mainly perform OPCAB in chronic dialysis patients and their intraoperative management has been established with an acceptable clinical outcome. In the present study, we investigated the preoperative and intraoperative confounding factors for chronic dialysis patients who underwent $\mathrm{OPCAB}$ and we assessed the impact of diabetic nephropathy and other possible risk factors on midterm survival after $\mathrm{OPCAB}$ in this population.

\section{Methods}

Patients

Among 1,050 consecutive patients undergoing OPCAB at the Department of Cardiovascular Surgery, National Cardiovascular Center, between February 2000 and April 2006, there were 41 patients on chronic dialysis (3.9\%). 
Table 1. Patient Demographics

\begin{tabular}{|c|c|c|c|}
\hline & $\begin{array}{c}\mathrm{DN} \\
(\mathrm{n}=29)\end{array}$ & $\begin{array}{l}\mathrm{NDN} \\
(\mathrm{n}=12)\end{array}$ & $\mathrm{P}$ value \\
\hline Duration of dialysis (years) & $4.2 \pm 5.5$ & $9.1 \pm 7.5$ & 0.02 \\
\hline Age (years) & $65.7 \pm 8.8$ & $67.9 \pm 7.6$ & NS \\
\hline $\mathrm{M} / \mathrm{F}$ & $23 / 6$ & $11 / 1$ & NS \\
\hline Hyperlipidemia & $7(24 \%)$ & $3(25 \%)$ & NS \\
\hline Hypertension & $12(41 \%)$ & $6(50 \%)$ & NS \\
\hline Arteriosclerosis obliterans & $9(36 \%)$ & $2(17 \%)$ & NS \\
\hline History of AAA & 0 & $4(33.3 \%)$ & 0.04 \\
\hline Calcified ascending aorta & $5(17 \%)$ & $3(25 \%)$ & NS \\
\hline COPD & 0 & 0 & NS \\
\hline $\begin{array}{l}\text { History of } \\
\quad \text { cerebrovascular disease }\end{array}$ & $5(20.8 \%)$ & $3(23.1 \%)$ & NS \\
\hline \multicolumn{4}{|l|}{ Extent of disease } \\
\hline 1VD & 0 & 0 & \\
\hline $2 \mathrm{VD}$ & $6(20.6 \%)$ & 0 & 0.05 \\
\hline 3VD & $15(51.7 \%)$ & $12(100 \%)$ & 0.05 \\
\hline Left main trunk disease & $3(10.3 \%)$ & $1(8.3 \%)$ & NS \\
\hline Mean no. of diseased vessels & $2.8 \pm 0.4$ & $2.7 \pm 0.6$ & NS \\
\hline LVEF $<30 \%$ & $7(24.1 \%)$ & 0 & 0.04 \\
\hline \multicolumn{4}{|l|}{ Valvular disease } \\
\hline Mitral (>Grade 3) & $1(3.4 \%)$ & 0 & NS \\
\hline Aortic (>Grade 3) & 0 & 0 & NS \\
\hline History of PCI & $4(13.7 \%)$ & $2(16.7 \%)$ & NS \\
\hline Previous MI & $11(37.9 \%)$ & $4(33.3 \%)$ & NS \\
\hline Unstable angina pectoris & $7(24.1 \%)$ & $4(33.3 \%)$ & NS \\
\hline Acute MI & $2(7.0 \%)$ & $1(8.3 \%)$ & NS \\
\hline Preoperative IABP & $3(10.3 \%)$ & $1(8.3 \%)$ & NS \\
\hline
\end{tabular}

DN, diabetic nephropathy; NDN, non-diabetic nephropathy; AAA, abdominal aortic aneurysm; COPD, chronic obstructive pulmonary disease; VD, vessel disease; LVEF, left ventricular ejection fraction; PCI, percutaneous catheter intervention; MI, myocardial infarction; IABP, intra-aortic balloon pumping.

These patients' preoperative characteristics are shown in Table 1: 29 (70.7\%) had diabetic nephropathy (DN group) and $12(29.3 \%)$ did not (NDN group). The causes of renal failure in the NDN group were chronic glomerulonephritis $(n=4)$, nephrosclerosis $(n=6)$ and unknown $(n=2)$. There were no significant preoperative differences between the $\mathrm{DN}$ and NDN groups except for duration of dialysis and cardiac function. At the time of operation, the duration of dialysis was longer in the NDN group $(9.1 \pm 7.5$ years $)$ than in the DN group $(4.2 \pm 5.5$ years $)(\mathrm{P}=0.028)$. Poor cardiac function (left ventricular ejection fraction $(\mathrm{LVEF})<30 \%$ ) was recognized only in the $\mathrm{DN}$ group $(\mathrm{P}=0.048)$.

Urgent operation was performed for 7 patients because of unstable angina or acute myocardial infarction with unstable hemodynamic conditions, and the remaining 34 patients underwent elective surgery in a stable condition.

Institutional approval for this study was obtained, and each patient gave informed consent to serve as a subject.

\section{Surgical Technique}

At the National Cardiovascular Center, OPCAB with extensive use of an arterial conduit has been performed since 2000 . In our recent series, total arterial revascularization by OPCAB achieved excellent patency in the early postoperative period and showed good clinical results, and for this reason we prefer to perform it. Our standard technique is composite grafting of the radial artery (RA) in combination with 1 or both internal thoracic arteries (ITA). ${ }^{6}$ In dialysis patients, however, the RA either needs to be reserved for shunt formation for dialysis or has already been used, so bilateral ITA composite grafting is often used for complete revascularization. The advantage of this method is that it
Table 2. Surgical Results

\begin{tabular}{lccc}
\hline & $\begin{array}{c}\mathrm{DN} \\
(\mathrm{n}=29)\end{array}$ & $\begin{array}{c}\mathrm{NDN} \\
(\mathrm{n}=12)\end{array}$ & P value \\
\hline Mean no. of bypass grafts & $3.0 \pm 0.8$ & $3.4 \pm 1.1$ & $\mathrm{NS}$ \\
Urgent & $5(17.2 \%)$ & $2(16.7 \%)$ & $\mathrm{NS}$ \\
All arterial grafts & $22(75.8 \%)$ & $6(50.0 \%)$ & 0.146 \\
Bilateral ITA use & $22(75.8 \%)$ & $3(25.0 \%)$ & $<0.0001$ \\
$\quad$ Composite grafting & $19(65.5 \%)$ & $2(16.6 \%)$ & 0.006 \\
All in-situ & $7(24.1 \%)$ & $3(25.0 \%)$ & $\mathrm{NS}$ \\
GEA use & $1(3.4 \%)$ & 0 & $\mathrm{NS}$ \\
Single ITA+GEA & 0 & $2(16.6 \%)$ & 0.08 \\
Single ITA+RA & $2(6.8 \%)$ & 0 & $\mathrm{NS}$ \\
Operation time (h) & $309 \pm 81$ & $307 \pm 35$ & $\mathrm{NS}$ \\
Graft patency & $100 \%(88 / 88)$ & $94 \%(30 / 32)$ & $\mathrm{NS}$ \\
Hospitalization (days) & $37 \pm 47$ & $36 \pm 48$ & $\mathrm{NS}$ \\
\hline
\end{tabular}

GEA, gastroepiploic artery; RA, radial artery. Other abbreviations see in Table 1.

avoids neurologic complications, because we use the aorta no-touch technique (ie, no side clamping of the diseased aorta). In high-risk patients, such as elderly patients, obese female patients and patients with chronic obstructive pulmonary disease (COPD), we occasionally use a single ITA plus either the saphenous vein (SV) or gastroepiploic artery (GEA) if they are in acceptable condition (Table 2).

\section{Definitions}

Early mortality was defined as any death occurring within 30 days after the operation or during the initial hospital stay, and late mortality was any death occurring after that. Development of congestive heart failure (CHF), fatal or non-fatal myocardial infarction, requirement for a cardiac intervention (redo-CABG, percutaneous transluminal coronary angiography etc) or sudden, unexplained death were all considered as cardiac events.

\section{Patient Follow-up}

Follow-up information was obtained from each patient's hospital record, interviews at the time of outpatient visits, telephone calls and from referring physicians.

\section{Statistical Analysis}

Comparison between groups was performed using the unpaired Student's t-test and the $\chi^{2}$ test for categorical variables. Actuarial survival and cardiac event-free survival was calculated by the Kaplan-Meier method. Cox proportional hazard models were used to determine the influence of patients' characteristics and operative data on late survival. Hazard ratios, 95\% confidence intervals, and levels of statistical significance ( $\mathrm{P}$ value) were calculated. All results were expressed as mean \pm standard deviation and $\mathrm{P}<0.05$ was considered statistically significant.

\section{Results}

\section{Perioperative Data}

Intraoperative data are shown in Table 2. There were no cases of conversion from OPCAB to $\mathrm{CABG}$ in either group. Complete revascularization was accomplished in all cases. Revascularization using only arterial grafts was more frequently performed in the DN group than in the NDN group $(\mathrm{P}=0.146)$. Bilateral ITAs were more often used in the DN group $(\mathrm{P}<0.001)$, as were composite grafts using only the left ITA $(\mathrm{P}=0.006)$. 
Table 3. Postoperative Morbidity

\begin{tabular}{lccc}
\hline & $\begin{array}{c}\mathrm{DN} \\
(\mathrm{n}=29)\end{array}$ & $\begin{array}{c}\mathrm{NDN} \\
(\mathrm{n}=12)\end{array}$ & P value \\
\hline Postoperative morbidity & $18(62.0 \%)$ & $7(58.3 \%)$ & $\mathrm{NS}$ \\
GI complication & $2(6.9 \%)$ & $2(16.7 \%)$ & $\mathrm{NS}$ \\
Infection & $7(29.2 \%)$ & $3(23.1 \%)$ & $\mathrm{NS}$ \\
Superficial wound & $4(13.8 \%)$ & $1(8.3 \%)$ & $\mathrm{NS}$ \\
Deep sternum & $1(3.4 \%)$ & 0 & $\mathrm{NS}$ \\
Respiratory & $2(6.9 \%)$ & 0 & $\mathrm{NS}$ \\
Stroke & $2(6.9 \%)$ & $1(8.3 \%)$ & $\mathrm{NS}$ \\
\hline
\end{tabular}

GI, gastrointestinal. Other abbreviations see in Table 1.

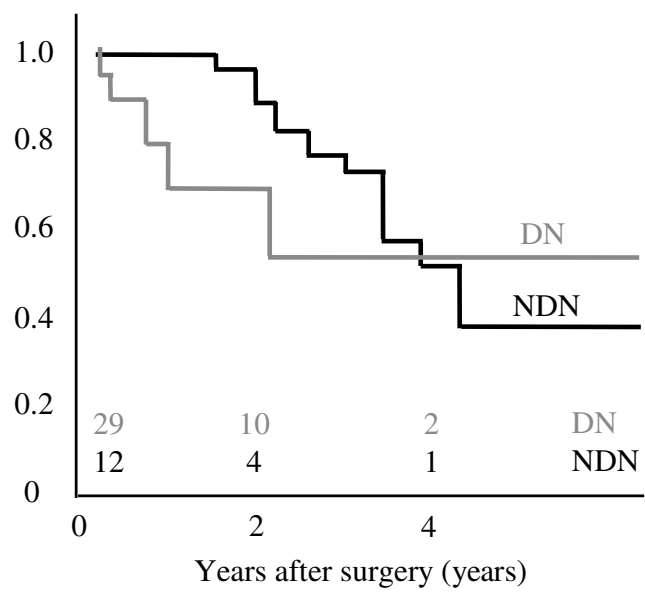

Figure 1. Freedom from any cardiac events after surgery between diabetic nephropathy (DN) and non-diabetic nephropathy (NDN) patients on dialysis.

Table 4. Postoperative Mortality

\begin{tabular}{lccc}
\hline & $\begin{array}{c}\mathrm{DN} \\
(\mathrm{n}=29)\end{array}$ & $\begin{array}{c}\text { NDN } \\
(\mathrm{n}=12)\end{array}$ & P value \\
\hline Hospital death & $2(6.9 \%)$ & $2(16.6 \%)$ & NS \\
Mediastinitis & $2(100 \%)$ & 0 & \\
GI complication & 0 & $2(100 \%)$ & \\
Late death & $11(37.9 \%)$ & $3(10.3 \%)$ & NS \\
Heart failure & $4(36.3 \%)$ & $1(33.3 \%)$ & \\
MI & $1(9.0 \%)$ & $1(33.3 \%)$ & \\
Respiratory complication & $1(9.0 \%)$ & 0 & \\
GI complication & $1(9.0 \%)$ & 0 & \\
SIRS & $1(9.0 \%)$ & 0 & \\
Unknown & $3(27.2 \%)$ & $1(33.3 \%)$ &
\end{tabular}

SIRS, systemic inflammatory response syndrome. Other abbreviations see in Tables 1,3 .

Postoperative coronary angiography was performed within 1 month after surgery in 33 patients $(80.5 \%$ : 23 patients in the DN group, 10 patients in the NDN group). All grafts (88/88) were patent in the DN group compared with 94\% (30/32) in the NDN group. Graft occlusion occurred in 2 patients in the NDN group: GEA-PL and RITA-D1. Neither patient had experienced any cardiac events after graft occlusion.

\section{Morbidities and Mortalities}

Operative morbidities are shown in Table 3. No differences were found in the incidence of postoperative morbidities, including mediastinitis and superficial wound problems.

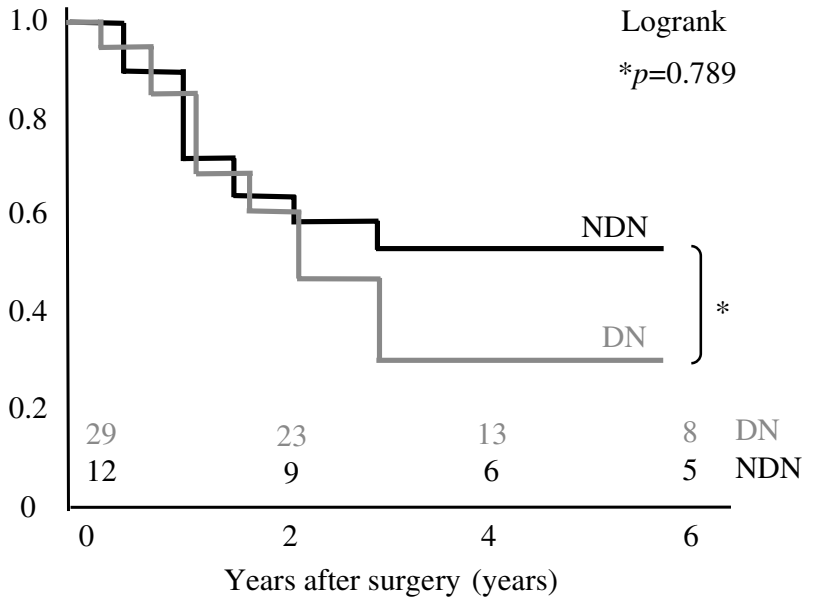

Figure 2. Survival after surgery between diabetic nephropathy (DN) and non-diabetic nephropathy (NDN) patients on dialysis.

Table 5. Preoperative and Intraoperative Confounding Factors for Cox Hazard Model

\begin{tabular}{ll}
\hline $\begin{array}{c}\text { Preoperative confounding } \\
\text { factors }\end{array}$ & $\begin{array}{c}\text { Intraoperative confounding } \\
\text { factors }\end{array}$ \\
\hline $\begin{array}{l}\text { Duration of dialysis (years) } \\
\text { Age }\end{array}$ & $\begin{array}{c}\text { Bilateral ITA } \\
\text { Functional complete revascularization }\end{array}$ \\
Diabetes & \\
Hyperlipidemia & \\
Hypertension & \\
ASO & \\
History of AAA & \\
Calcified ascending aorta \\
COPD \\
History of cerebrovascular disease \\
3VD \\
Left main trunk disease \\
LVEF <30\% \\
History of PCI \\
Previous MI \\
Unstable angina pectoris \\
Acute myocardial infarction \\
Preoperative IABP
\end{tabular}

ASO, arteriosclerosis obliterans; ITA, internal thoracic artery. Other abbreviations see in Table 1 .

Table 6. Cox Proportional Hazard Model for Death at Midterm Follow-up

\begin{tabular}{lccc}
\hline & HR & $95 \%$ CI & P value \\
\hline Age & 0.534 & $0.306-0.890$ & 0.016 \\
ASO & 0.367 & $0.194-0.681$ & 0.002 \\
History of AAA & 0.475 & $0.238-1.053$ & 0.064 \\
No. of diseased vessels & 0.364 & $0.112-1.215$ & 0.098 \\
\hline
\end{tabular}

HR, hazard ratio; CI, confidence interval. Other abbreviations see in Tables 1, 5 .

Mediastinitis occurred only in patients from the DN group who had had both ITAs harvested.

Freedom from cardiac event is shown in Figure 1. The actuarial freedom from postoperative cardiac events among the DN group was $92 \%$ at 1 year, $60 \%$ at 3 years and $28 \%$ at 5 years, whereas in the NDN group it was $60 \%, 45 \%$ and $43 \%$, respectively. There were no statistical differences 
between the 2 groups. The linearized rate of postoperative cardiac events was 18.03 events per 100 patient-years in the DN group and 18.23 events per 100 patient-years in the NDN group, which showed no significant difference between the 2 groups ( $\mathrm{P}>0.999)$.

Early and late mortalities are shown in Table 4. Early death occurred in 2 patients in the DN group $(6.9 \%$; mediastinitis caused by methicillin-resistant Staphylococcus aureus) and in 2 patients in the NDN group (16.7\%; gastrointestinal complications $)(\mathrm{P}=0.349)$.

There were $11(37.9 \%)$ late deaths in the DN group and $3(25.0 \%)$ in the NDN group $(\mathrm{P}=0.439)$. The most frequent cause of death in the DN group was heart failure associated with dialysis cardiomyopathy, which was caused by longterm dialysis.

The actuarial survival after operation in the DN group was $85 \%$ at 1 year, $45 \%$ at 3 years, and $30 \%$ at 5 years, compared with $71 \%, 49 \%$, and $49 \%$, respectively, in the NDN group (Figure 2). There was no significant difference between the 2 groups $(\mathrm{P}=0.789)$. Cox proportional hazard models were used to assess the effect of preoperative and intraoperative confounding factors (Table 5) on late death. As shown in Table 6, the significant predictors of late death were arteriosclerosis obliterans (ASO) $(\mathrm{P}=002)$ and age ( $>65$ years $)(\mathrm{P}=0.016)$.

\section{Discussion}

In the current era, diabetes is the most common reason for dialysis. According to a recent overview of dialysis treatment in Japan, diabetic nephropathy constitutes the highest proportion $(42.9 \%)$ of primary renal diseases in patients who began dialysis, which is approximately twice as much compared with 20 years ago. ${ }^{7}$ Cardiovascular disease is the major cause of death, accounting for more than $50 \%$ of cases. ${ }^{8-11}$ In addition to significantly developed cardiovascular disease prior to the initiation of dialysis, the tissue deposition of advanced glycosylation end-products may also have an influence on cardiovascular mortality once dialysis has begun. ${ }^{12-14}$ Based on these facts, adequate treatment for cardiovascular disease is the key to better prognosis for these patients.

Several recent reports on survival of patients with chronic dialysis after $\mathrm{CABG}^{4,15-26}$ have demonstrates the operation can be performed with an acceptable mortality and morbidity for dialysis patients. ${ }^{16,17,19,23,24,26}$ Herzog et al reported that dialysis patients have better long-term survival after $\mathrm{CABG}$ surgery than after percutaneous coronary intervention, especially diabetic patients. ${ }^{23}$

In Japan, OPCAB is currently the most common strategy for patients with coronary artery disease. According to the registry of the Japanese Association for Thoracic Surgery in $2006,64 \%$ of patients on chronic dialysis had undergone $\mathrm{OPCAB}$ and mortality for patients on dialysis was $8.5 \%$, whereas hospital mortality was $6.4 \% .^{1}$ In the present study, hospital mortality was $6.9 \%$ in the DN group and $16.7 \%$ in the NDN group, both of which were higher than the hospital mortality of patients without dialysis, which was $1.9 \%$.

With regard to the preoperative characteristics, there were several differences between the DN and NDN groups. The period from initiation of dialysis to surgery in the DN group was significantly shorter than that of the NDN group $(\mathrm{P}=0.02)$. Preoperative left ventricular function in the $\mathrm{DN}$ group was significantly lower than in the NDN group $(\mathrm{P}=$ $0.04)$.
The surgical strategy, including graft selection, may be an important predictor for outcome of these patients. We use an arterial composite graft to achieve complete revascularization and avoid side-clamping of the diseased ascending aorta (ie, the aorta no-touch technique). In general, the use of a total arterial graft with bilateral ITAs has an advantage for long-term graft patency. ${ }^{27-31}$ Recent reviews demonstrate that using the bilateral ITAs is effective for both diabetic and dialysis patients; 29,30 however, their use in diabetic patients, especially those on chronic dialysis, has the potential risk of mediastinitis. We had only 1 case of deep sternal infection $(2.4 \%)$, which was in the DN group (bilateral ITAs were used for this patient). A skeletonized technique is preferable for reducing the risk of mediastinitis or other sternal wound problems in patients with poor risks, such as diabetes and renal failure. ${ }^{29-31}$ Regarding graft selection in diabetic patients on dialysis, the RA is not available because of its use as a primary arteriovenous fistula for vascular access. The SV and GEA are also less available because of severe arteriosclerosis of the abdominal aorta or/and ASO. For these reasons we generally use the bilateral ITAs even in diabetic patients on dialysis.

Cox proportional hazard models were performed to assess the predicted factors for late death because there were several critical biases in both the preoperative and intraoperative conditions. As analyzed by the Kaplan-Meier method, diabetes was not a predicted risk factor in this population. Use of bilateral ITAs and complete revascularization were expected to be important factors for the survival, but, unexpectedly, the Cox model did not show any influence on midterm survival in this population. On the other hand, ASO and aging were the predicted risk factors in this population, which is a reasonable result because the presence of ASO suggests general progressive arteriosclerosis, not to mention aging. 32

We also analyzed the actuarial survival of the diabetic and non-diabetic patients when patients with low cardiac function (LVEF <30\%) are excluded. The result was that there was no significant difference between these patients $(\mathrm{P}=0.935)$.

\section{Study Limitations}

This was a retrospective study and had a relatively small number of patients. Longer follow-up and a larger number of patients will be necessary in order to obtain stronger evidence.

In conclusion, the midterm survival of both diabetic and non-diabetic nephropathy patients on chronic dialysis after OPCAB was acceptable. Multivariate analysis suggests that diabetes is not a predicted risk factor for OPCAB in chronic dialysis patients, whereas peripheral arterial disease and aging are.

\section{Acknowledgments}

We thank Dr Ryoji Chiba (Department of Pathology and Laboratory Medicine, Sendai Kousei Hospital) for his assistanse with the statistical analysis.

\section{References}

1. Ueda U, Fujii Y, Udagawa H. Thoracic and Cardiovascular Surgery in Japan during 2006: Annual report by the Japanese Association for Thoracic Surgery. Gen Thorac Cardiovasc Surg 2008; 56: 365-388.

2. Hamaguchi S, Tsuchihashi-Makaya M, Kinugawa S, Yokota T, Ide T, Takeshita A, et al. Chronic kidney disease as an independent risk for long-term adverse outcomes in patients hospitalized with heart 
failure in Japan. Circ J 2009; 73: 1442-1447.

3. Adler AI, Stevens RJ, Manley SE, Bilous RW, Cull CA, Holman $\mathrm{RR}$, on behalf of the UKPDS Group. Development and progression of nephropathy in type 2 diabetes: The United Kingdom Prospective Diabetes Study (UKPDS 64). Kidney Int 2003; 63: 225-232.

4. Calafiore AM, Di Mauro M, Di Giammarco G, Contini M, Vitolla G, Iaco AL, et al. Effect of diabetes on early and late survival after isolated first coronary bypass surgery in multivessel disease. $J$ Thorac Cardiovasc Surg 2003; 125: 144-154.

5. Ito S, Murai S, Sugiura M, Yoshida T, Fukutomi T. Predictors of congestive heart failure in patients on maintenance hemodialysis. Circ J 2007; 71: 1424-1429.

6. Tagusari O, Kobayashi J, Bando K, Niwaya K, Nakajima H, Nakatani $\mathrm{T}$, et al. Total arterial off-pump coronary artery bypass grafting for revascularization of the total coronary system: Clinical outcome and angiographic evaluation. Ann Thorac Surg 2004; 78: 1304-1311.

7. Nakai S, Masakane I, Akiba T, Shigematsu T, Yamagata K, Watanabe $\mathrm{Y}$, et al. Overview of regular dialysis treatment in Japan as of 31 December 2006. Ther Apher Dial 2008; 12: 428-456.

8. Brunner FP, Selwood NH, on behalf of the EDTA Registration Committee. Profile of patients on RRT in Europe and death rates due to major causes of death groups. Kidney Int Suppl 1992; 38: S4.

9. Dikow R, Ritz E. Cardiovascular complications in the diabetic patients with renal disease: An update in 2003. Nephrol Dial Transplant 2003; 18: $1993-1998$

10. Tzamaloukas AH, Yuan ZY, Balaskas E, Oreopoulos DG. CAPD in end stage patients with renal disease due to diabetes mellitus: An update. Adv Perit Dial 1992; 8: 185.

11. Ishio N, Kobayashi Y, Takebayashi H, Iijima Y, Kanada J, Nakayama $\mathrm{T}$, et al. Impact of drug-eluting stents on clinical and angiographic outcomes in dialysis patients. Circ J 2009; 71: 1525-1529.

12. United States Renal Data System. Experts from the USRDS 2007 annual data report: Atlas of end-stage renal disease in the United States. Am J Kidney Dis 2008; 51(Suppl I): S1.

13. Wolfe RA, Gaylin DS, Port FK, Held PJ, Wood CL. Using USRDS generated mortality tables to compare local ESRD mortality rates to national rates. Kidney Int 1992; 42: 991-996.

14. Unites States Renal Data System. Excerpts from the USRDS 2005 annual data report: Atlas of end-stage renal disease in the United States. Am J Kidney Dis 2006; 47(Suppl 1): S1.

15. Leavitt BJ, Sheppard L, Maloney C, Clough RA, Braxton JH, Charlsworth DC, et al. Effect of diabetes and associated conditions on long-term survival after coronary artery bypass graft surgery. Circulation 2004; 110(Suppl 2): 41-44.

16. Hosoda Y, Yamamoto T, Takazawa K, Yamasaki M, Yamamoto S Hayashi I, et al. Coronary artery bypass grafting in patients on chronic hemodialysis: Surgical outcome in diabetic nephropathy versus nondiabetic nephropathy patients. Ann Thorac Surg 2001; 71: 543-548.

17. Hirose H, Amano A, Takahashi A, Takanashi S. Coronary artery bypass grafting in patients on chronic hemodialysis: Diabetic nephropathy versus nondiabetic nephropathy. Artif Organs 2002; 26: $794-$ 801.

18. Rajakaruna C, Rogers CA, Suranimala C, Angelini GD, Ascione R.
The effect of diabetes mellitus on patients undergoing coronary surgery: A risk-adjusted analysis. J Thorac Cardiovasc Surg 2006; 132: $802-810$

19. Fukushima S, Kobayashi J, Tagusari O, Bando K, Niwaya K, Nakajima H, et al. Early results of off-pump coronary artery bypass grafting for patients on chronic renal dialysis. Jpn J Thorac Cardiovasc Surg 2005; 53: 186-192.

20. Chukwuemeka A, Weisel A, Maganti M, Nette AF, Wijeysundera $\mathrm{DN}$, Beattie WS, et al. Renal dysfunction in high-risk patients after on-pump and off-pump coronary artery bypass surgery: A propensity score analysis. Ann Thorac Surg 2005; 80: 2148-2154.

21. Choi J, Cho K, Kim K. Does diabetes affect the postoperative outcomes after total arterial off-pump coronary bypass surgery in multivessel disease? Ann Thorac Surg 2005; 80: 1353-1361.

22. Le Feuvre C, Borentain M, Beygui F, Helft G, Batisse JP, Metzger JP. Comparison of short-and long-term outcomes of coronary angioplasty in patients with and without diabetes mellitus and with and without hemodialysis. Am J Cardiol 2003; 92: 721-725.

23. Herzog CA, Ma JZ, Collins AJ. Comparative survival of dialysis patients in the United States after coronary angioplasty, coronary artery stenting, and coronary artery bypass surgery and impact of diabetes. Circulation 2002; 106: 2207-2211.

24. Franga DL, Kratz JM, Crumbley AJ, Zellner JL, Stroud MR, Crawford FA. Early and long-term results of coronary artery bypass grafting in dialysis patients. Ann Thorac Surg 2000; 70: 813-819.

25. Magee MJ, Dewey TM, Acuff T, Edgerton JR, Hebbeler JF, Prince SL, et al. Influence of diabetes on mortality and morbidity: Off-pump coronary artery bypass grafting versus coronary artery bypass grafting with cardiopulmonary bypass. Ann Thorac Surg 2001; 72: 776-781.

26. Beckermann J, Van Camp J, Li S, Wahl SK, Collins A, Herzog CA. On-pump versus off-pump coronary surgery outcomes in patients requiring dialysis: Perspectives from a single center and the United States experience. J Thorac Cardiovasc Surg 2006; 131: 1261-1266.

27. Buxton BF, Komeda M, Fuller JA, Gordon I. Bilateral internal thoracic artery grafting may improve outcome of coronary artery surgery. Circulation 1998; 98(Suppl): II-1-II-6.

28. Nakayama Y, Sakata R, Ura M. Bilateral internal thoracic artery use for dialysis patients: Does it increase operative risk? Ann Thorac Surg 2001; 71: 783-787.

29. Kai M, Hanyu M, Soga Y, Nomoto T, Nakano J, Matsuo T, et al. Off-pump coronary artery bypass grafting with skeletonized bilateral internal thoracic arteries in insulin-dependent diabetics. Ann Thorac Surg 2007; 84: 32-37.

30. Kai M, Okabayashi H, Hanyu M, Soga Y, Nomoto T, Nakano J, et al. Long-term results of bilateral internal thoracic artery grafting in dialysis patients. Ann Thorac Surg 2007; 83: 1666-1671.

31. Pevni D, Uretzky G, Mohr A, Braunstein R, Kramer A, Paz Y, et al. Routine use of bilateral skeletonized internal thoracic artery grafting: Long-term results. Circulation 2008; 118: 705-712.

32. Norgren L, Hiatt WR, Dormandy JA, Nehler MR, Harris KA, Fowkes FG; TASC II Working Group. Inter-Society Consensus for Management of Peripheral Arterial Disease (TASC II). J Vasc Surgery 2007; 45(Suppl S): S8-S13. 